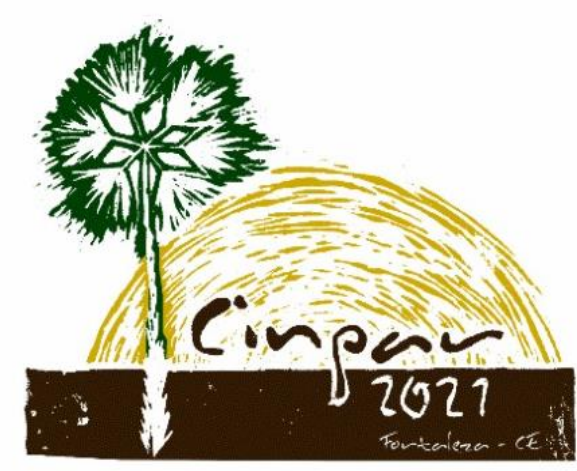

XVII Congresso Internacional sobre Patologia e Reabilitação das Construções

XVII Congreso Internacional sobre Patología y Rehabilitación de las Construcciones

XVII International Conference on Pathology and Constructions Rehabilitation

FORTALEZA (Brasil), 3 a 5 de junho de 2021

https://doi.org/10.4322/CINPAR.2021.161

\title{
Análise das Manifestações Patológicas na Igreja de Santa Edwirges na Cidade de Fortaleza no Estado do Ceará no Brasil
}

\section{Analysis of Pathological Manifestations in the Church of Santa Edwirges in the City of Fortaleza in the state of Ceará in Brazil}

\author{
Juscelino Chaves SALES ${ }^{1}$ \\ ${ }^{1}$ Universidade Estadual Vale do Acaraú, Sobral, Brasil, juscelinochaves@hotmail.com ${ }^{1}$
}

\begin{abstract}
Resumo: Ao longo dos séculos principalmente nos países do ocidente foram construídas várias igrejas católicas, e isso ocorreu devido principalmente a religião católica ser a religião mais difundida do ocidente. Muitas dessas igrejas já duram séculos como a Catedral de Notre Dame em Paris que já tem mais 860anos de existência. Sabemos que ao longo do tempo vão aparecendo as manifestações patológicas nas igrejas mesmo com uma manutenção feita corretamente. $O$ ambiente em que essas edificações foram construídas também aumentam as manifestações patológicas. O presente trabalho faz uma análise das manifestações patológicas existentes na Igreja de Santa Edwirges na cidade de Fortaleza que está localizada na avenida Leste-Oeste. Pôr a igreja está localizada em uma praia foi possível perceber o ataque do spray (marinho) da água do mar que contêm sal $(\mathrm{NaCl})$ aumentando assim as manifestações patologias como corrosão de armadura, deslocamento de revestimento cerâmico, eflorescência, deslocamento do reboco das paredes etc., que ocorrem com maior frequência, onde também é feita a manutenção periódica com mais frequência. Através das visitas in loco foi possível constatar também que quase todos os anos, com a ressaca do mar ocorre a danificação do enroncamento feito de pedras e das grades de proteção feita de blocos cerâmicos argamassados, com os corrimões de aço que protegem a igreja e a edificação paroquial.
\end{abstract}

Palavras-chave: Igreja de Santa Edwirges, spray marinho, manifestações patológicas, corrosão de armadura.

\section{Introdução}

As patologias de construção são manifestações na forma de trincas, fissuras, rachaduras, manchas, desagregações e outros tipos que se apresentam em edificações construidas (Santos, 2018).

$\mathrm{O}$ estudo das patologias de edificações mostra-se bastante importante, pelo fato de uma edificação com patologias estar diretamente ligado a saúde dos usuários e também a sua segurança. Algumas dessas patologias encontradas nas edificações causam problemas de saúde enquanto outras ainda mais sérias, encontradas nas estruturas da edificação podem ocasionar colapso da mesma, comprometendo gravemente a segurança dos usuários que vivem no local (Vascoscelos, 2018)

Foi possivel analizar em cinco escolas no municipio de Sobral as manifestações patológicas onde se encontrou as seguintes patologias: trincas, rachaduras, exposição e oxidação de armaduras, infiltração de água e eflorescência. As causas levantadas como as prováveis responsáveis pelo surgimento dessas patologias ou de suas evoluções foram: infiltração, vazamentos, falta de impermeabilização, erros de cálculo, falhas de execução, dilatação térmica e, principalmente, falta de manutenção periódica (Santos, 2018).

As manifestações patológicas podem se fazer presentes em qualquer edificação, quer seja pelo processo executivo, especificação errônea de materiais e até mesmo com o passar do tempo devido à ausência de manutenção ou o uso inadequado do imóvel. O método utilizado para a correção destas deformações plásticas está diretamente relacionado a qual tipo de construção se trata (Teodoro, 2020). 
Edificios públicos no Brasil apresentam uma série de manisfestações patológicas decorrentes de erros de projeto, execução mal feita, a utilização de materiais de baixa qualidade e principalmente de falhas de manutenção e de falta de verbas para realizar essas manutenções.

Um pesquisador fez uma análise interessante mostrando as manifestações patológicas em uma edificação antiga que é a Catedral (Igreja) da Sé localizada na cidade de Fortaleza (Sales, 2014).

Foi feita uma avaliação da durabilidade de concretos estruturais produzidos segundo as prescrições da NBR 6118:2007, quando expostos à névoa salina da Praia do Futuro, em Fortaleza, onde foi constado que o spray das ondas (nevoa salina) aumenta a manifestação patológica de corrosão na armadura nas edificações feitas de concreto armado, localizadas próximas a praia do Futuro (Portela, 2013).

Campos (2014) fez um mapeamento do teor de íons cloro no ar atmosférico de Fortaleza/CE, e foi possivel constatar que os íons cloro no ar atingem as edificações localizadas próximas as praias na cidade de Fortaleza. Pesquisadores estudaram as manifestações patológicas causadas por construções decorrentes das edificações vizinhas e proporam solções técnicas para restabelecer as condições iniciais das construções vizinhas, como reforço das fundações, tratamento de fissuras e trincas em estruturas de concreto e alvenarias (Pinho, 2011).

Foi possivel perceber patologias estruturais ocasionadas por falhas de execução e imcompatibilidade entre os projetos aequitetonicos e estruturais (Roberto, 2011).

As manifestações patológicas encontradas nas edificações são geradas por falhas na concepção do projeto, na execução e com o passar do tempo na falta de manutenção adequada. Alguns fatores ambientais também tem influencias nessas manifestações (Silveira, 2021).

Foi realizada analise das edificações existentes no acampamento Joia localizado em uma ilha dentro de açude na cidade de Cruz no estado do Ceará onde a incidência de manifestações ocasionadas pela umidade excessiva foi também bastante decorrente, tais como eflorescência, mofo e bolor como também desagregação do reboco. Além disso foram observadas corrosão nos pilares, desplacamento de revestimento cerâmico, e cupins nas janelas, portas, e nas cobertas (Vascoscelos, 2018).

Foi realizada a análise de manifestações patológicas na Igreja Menino Deus em Sobral no estado do Ceará. Durante dois anos a igreja permaneceu fechado ao público, até que no ano de 2019, a Prefeitura de Sobral abriu um processo licitatório para a reforma total da Igreja do Menino Deus (Carneiro, 2020).

Um pesquisador expor todas as características e especificidades técnicas no que diz respeito às vistorias feitas in loco em instalações prediais, e fez descrição dos tipos de patologias existentes, sejam elas para algumas edificações residenciais, comerciais e públicas da cidade de Cruz localizada no estado do Ceará (Silveira, 2021).

Muitos reparos foram feitos em toda a Igreja Menino Deus em Sobral, que mitigaram os problemas nela encontrados, porém nenhum desses obteve pleno êxito, visto que as manifestações patológicas, voltaram a acontecer. Além disso, vários recursos financeiros, foram usados para tais reformas, mostrando um mal aproveitamento das economias (Carneiro, 2020).

O presente trabalho tem como objetivo fazer uma análise das manifestações patológicas existentes na Igreja (Capela) de Santa Edwirges e na edificação paroquial mostrando o porquê dessas manifestações patológicas acontecerem com uma maior frequência.

\section{Metodologia}

Para a realização deste trabalho foram feitas visitas in loco a Igreja de Santa Edwirges e a edificação paroquial na cidade de Fortaleza que está localizada na Avenida Leste-Oeste em uma área da praia, onde foram feitos registros fotográficos, sendo feito a partir daí um mapeamento das manifestações patológicas na igreja como também no edifício paroquial. Também foi feita uma pesquisa de cunho bibliográfico sobre manifestações patológicas em artigos, trabalhos de conclusão de curso, dissertações etc.

\section{Manifestações patológicas na Igreja de Santa Edwirges}

A Igreja (Capela) de Santa Edwirges está localizada na praia na Avenida Leste-Oeste proximo ao centro da cidade de Fortaleza e foi inaugura no dia 1 de outubro de 1999 tendo como primeiro pároco (vigário) o padre (sacerdote) Manoel de Castro Ferreira e o bispo da Arquidiocese de Fortaleza era o Cardeal Dom Aloisio Lorscheider. A Figura 1 mostra a placa de inauguração da Igreja (Capela) de Santa Edwirges. 


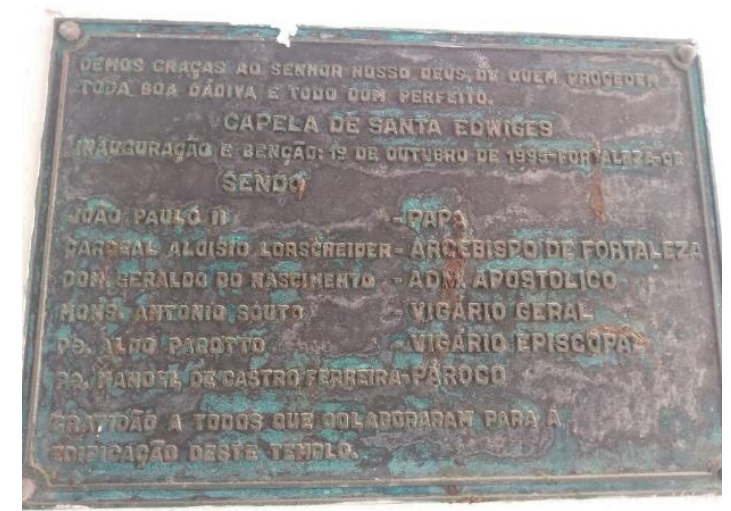

Figura 1 - Placa de inauguração da Igreja (Capela) de Santa Edwirges. Fonte: própia, 2018.

A Igreja de Santa Edwirges na cidade de Fortaleza está localizada na avenida Leste-Oeste no bairro LesteOeste no local chamado Oitão Preto, e fica entre a avenida e a praia também chamada de Leste Oeste. A igreja de Santa Edwirges foi construída distando cerca de $8 \mathrm{~m}$ do mar construída em uma área da praia onde foram colocadas pedra para evitar o avanço do mar sobre a de Santa Edwirges no tempo da ressaca do mar. Vale ressaltar que a área onde a Igreja (Capela) de Santa Edwirges foi construída pertence a Marinha do Brasil.

Mais de uma vez durante o ano é feita manuntenção na edificação para tirar a corrosão nas armaduras e deterioração nas paredes. O concreto solta (descasca) e depois aparecem a armadura com ferrugem e estando ela corroída, faz-se necessária a manutenção.

A Figura 2 foi possivel perceber a armadura (vergalhão de aço) exposta de um pilar com elevado grau de corrosão da armadura, onde a cerâmica de revestimento foi desplacada. O destacamento da cerâmica de revestimento foi ocasionado pela corrosão da armadura e da retirada do cobrimento de concreto sobre da armadura. Também é possivel perceber o inicio da corrosão na laje em balanço do primeiro pavimento da edificação paroquial.

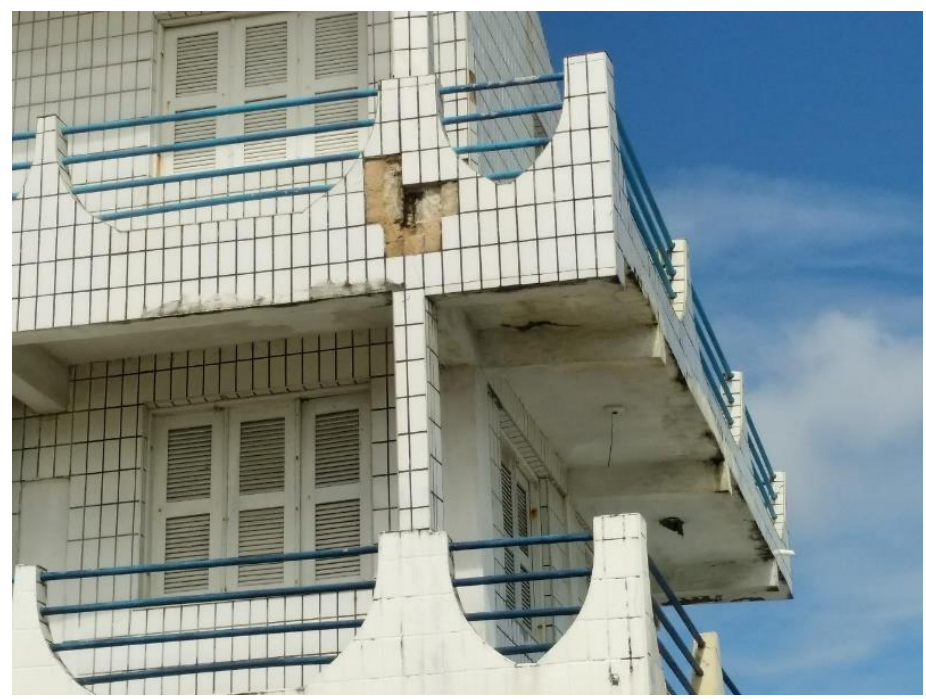

Figura 2 - Armadura (vergalho de aço) exposta de um pilar com elevado grau de corrosão. Fonte:própia, 2018.

A Igreja (Capela) de Santa Edwirges de Fortaleza foi construida em uma arquitetura diferente de quase a totalidade das igrejas católicas construidas no mundo, pois ela não possui torres e tem o pé direito interno da edificação muito baixo. A Figura 3 mostra a entrada da Igreja (Capela) de Santa Edwirges e em frente à mesma é possivel perceber um corrimão pintado de cor azul feito de aço já com pontos de corrosão. 


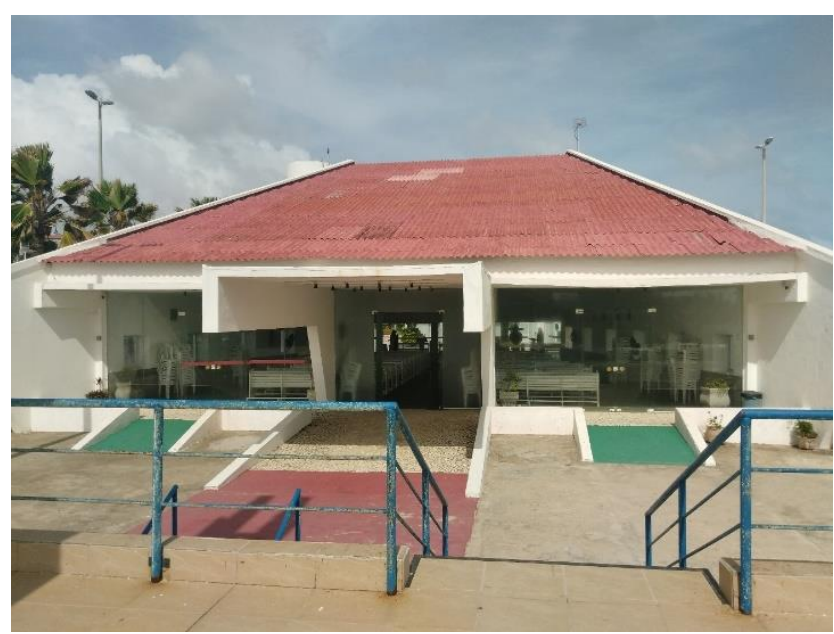

Figura 3 - Entrada da Igreja de Santa Edwirges e o corrimão pintado de cor azul feito de aço já com pontos de corrosão. Fonte: própia, 2018.

A Figura 4 mostra a Igreja de Santa Edwirges que não foi construída com torres como eram construídas as antigas igrejas católicas. A Igreja de Santa Edwirges foi construída com uma arquitetura dita moderna porém não seguiu as orientações da própria Igreja católica que quer que todas as suas igrejas sejam construídas com torres. Foi possível perceber que a igreja tem o pé direito baixo. Também foi possivel perceber que na parte de traz, a cerca de $10 \mathrm{~m}$ atrás da Igreja de Santa Edwirges se encontra o edifício paroquial (casa paroquial) de dois pavimentos. Foi possivel perceber também que devido a proximidade do mar que se não fosse o enrocamento feito de pedra em uma maré alta a agua poderia chegar dentro da Igreja de Santa Edwirges, o que acarretaria sérios problemas na edificação devido a umidade e a água salgada.

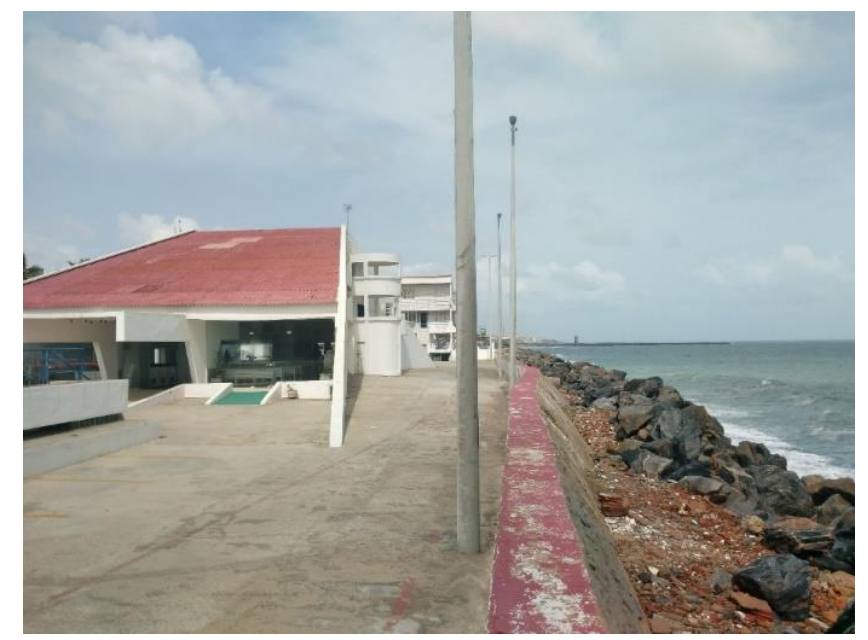

Figura 4 - Igreja de Santa Edwirges que não foi construída com torres. Fonte: própia, 2018.

A Figura 5 mostra descascamento do reboco que é uma manifestação patológica decorrente também da ação da maresia, localizada em alguns pontos da parte lateral da edificação, onde também é possivel perceber a janela com a esquadria de aluminio, sendo que a esquadria de aluminio não sofre nenhum tipo de patologia como a corrosão. 


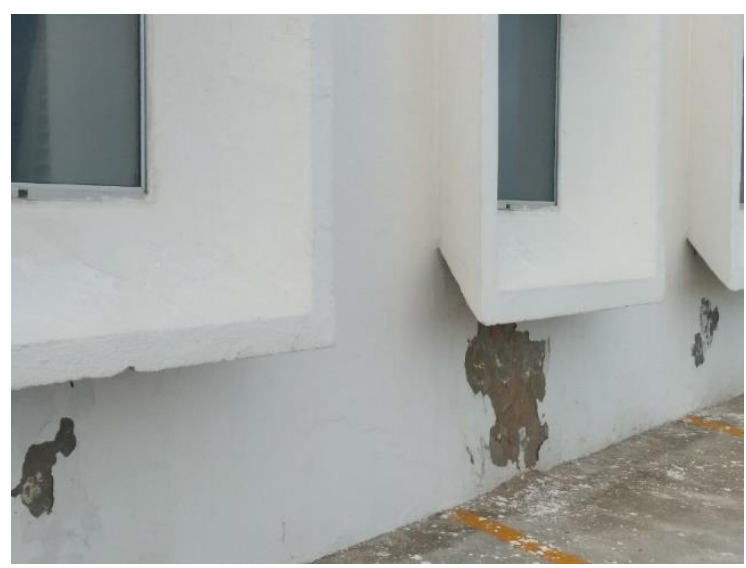

Figura 5 - Descascamento do reboco. Fonte: própia, 2018.

Foi possivel perceber corrosão na armadura das lajes da edificação paroquial, como também locais onde o procoesso de deterioração já em andamento em uma viga que sustenta a laje do segundo pavimento onde é possivel perceber o revestimento cerâmico já em processo de deterioração e corrosão nos corrimãos feitos de aço (Figura 6).

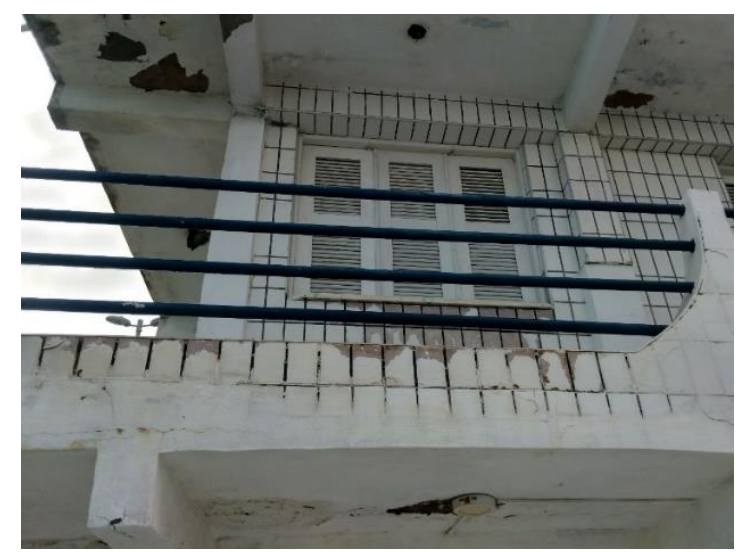

Figura 6 - Armadura das lajes da edificação com procoesso de deterioração. Fonte: própia, 2018.

Todos os anos existe uma epoca do ano em que a maré alta gera problemas patológicos na edificação acarretando destruição da proteção da edificação como também no enroncamento que foi colocado para suportar o avanço do mar. A estatuta de Santa Edwirges pode ser vista atrás da edificação paroquial (Figura 7).

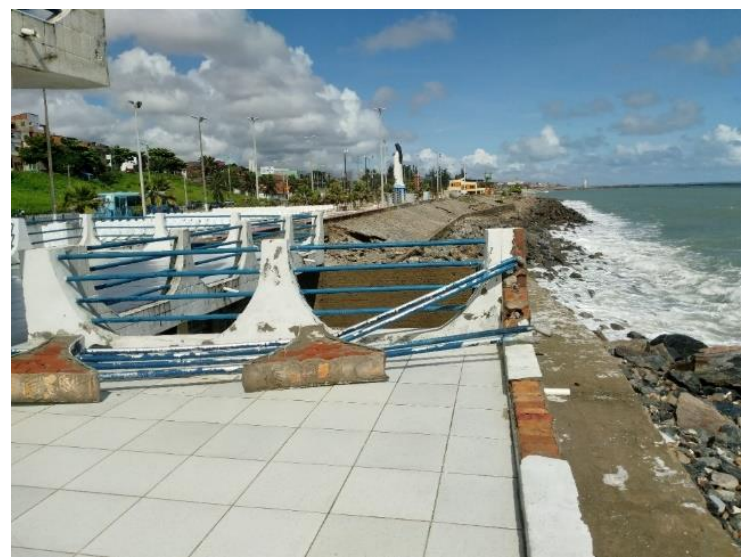

Figura 7 - Destruição da proteção da edificação como também no enroncamento pelas ondas. Fonte: própia, 2018. 
$\mathrm{Na}$ janela da Igreja de Santa Edwirges foi possivel perceber a corrosão acelerada dos parafusos que fixa a esquadria de aluminio que não corroi mesmo em um ambiente agressivo decorrete da maresia. Isso ocorre dedido ao ataque dos ionscloretos vindo do spray das ondas. Também foi possivel perceber o descascamento da pintura tanto do muro de proteção como na parede da janela da Igreja de Santa Edwirges (Figura 8).

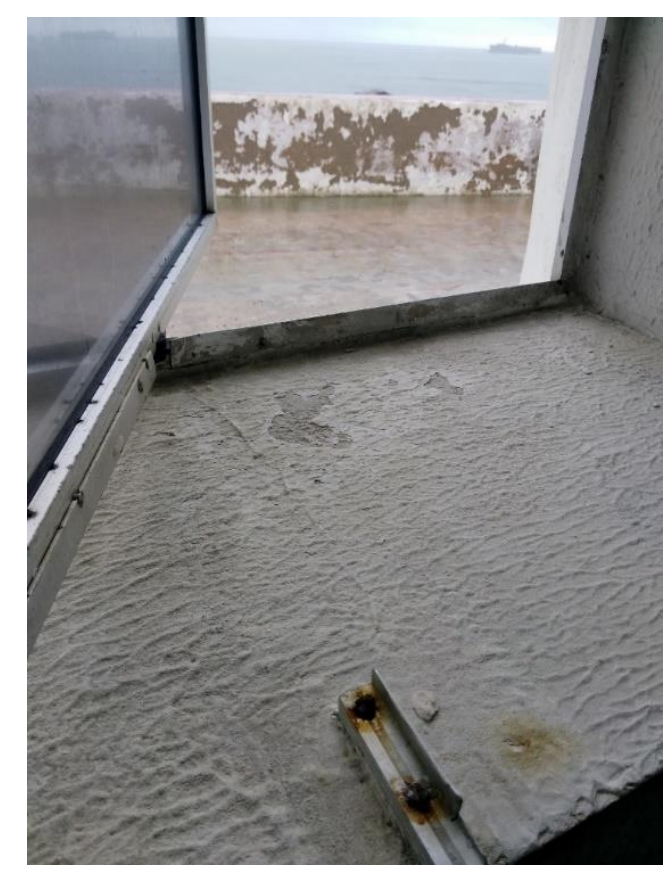

Figura 8 - Corrosão acelerada dos parafusos que fixa a esquadria de aluminio na janela. Fonte: própia, 2018.

Na Figura 09 foi possivel perceber o descolamento do reboco de revestimento da parede de uma coluna na frente da Igreja de Santa Edwirges, que pose ter sido devido ocasionada devido à má qualidade dos materiais, a açao do spray ocasionado pelas ondas, a mão de obra inadequada na execução e também pode ter ocorrido a expansão devido a umidade.

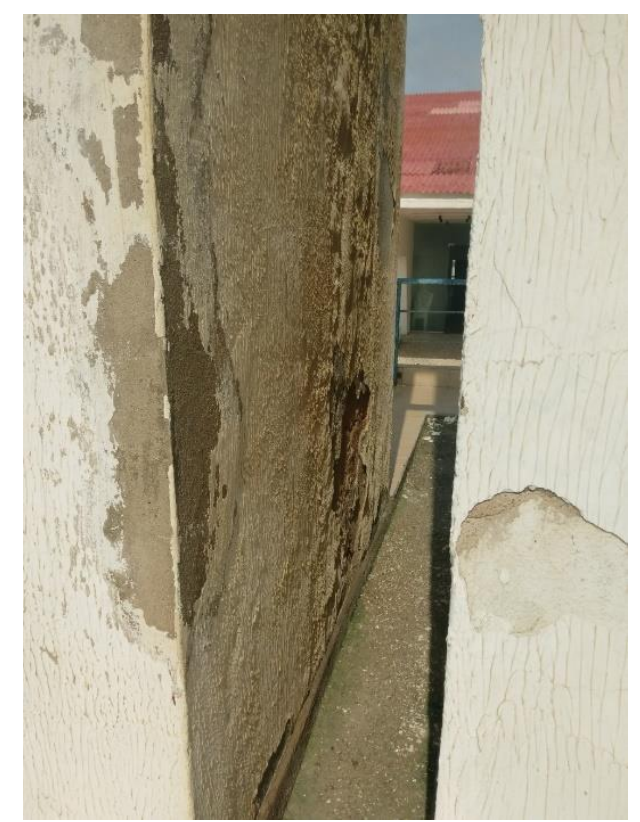

Figura 09 - Descolamento do reboco de revestimento da parede. Fonte: própia, 2018.

Em seus 21 anos de existencia a Igreja (Capela) de Santa Edwirges de Fortaleza já passou por diversas manutenções para solucionar a manifestações patológicas decorrente principalmente da nevoa marinha (gerando ions cloretos) que ataca as estruturas como também a cerca feita de aço que proteje a igreja todos 
os equipamentos feitos de aço de uma maneira mais severa acelerando a corrosão tanto nas armaduras como nos equipamentos (portões, cerca de proteção).

\section{Conclusão}

Como a Igreja de Santa Edwirges está localizada em uma praia a edificação sofre com o ataque dos ionscloretos devido a névoa marinha, em seus equipamentos, ou seja, devido ao spray gerado pelas ondas do mar. A maresia que nas praias do Estado do Ceará está entre as maiores do mundo vem atacando principalmente as armaduras de concreto e os equipamentos feitos de aço como os portões e corrimões, onde foi possivel perceber que a cerca feita de aço que separa a Igreja de Santa Edwirges da calçada da Avenida Leste- Oeste apresentou corrosão excessiva como também as armaduras do pilar e das lajes do edifício paroquial.

Foi possivel perceber que a manutenção das edificações (Igreja de Santa Edwirges e a edificação paroquial) é realizada com maior frequencia pela paróquia.

As principais manifestações patológicas encontradas na Igreja (Capela) de Santa Edwirges, foram corrosão na armadura, corrosão nos equipamentos de aço e desplacamento de revestimento (reboco).

\section{Referências}

Campos, A. M. R. (2014). Mapeamento do teor de íons cloro no ar atmosférico de Fortaleza/CE. Dissertação (Mestrado em Engenharia Civil: Estruturas e Construção Civil) - Universidade Federal do Ceará. Brasil.

Carneiro, R. R. (2020). Análise de manifestações patológicas na Igreja Menino Deus em Sobral- CE. Monografia. Curso de Engenharia Civil. Universidade Estadual Vale do Acaraú (UVA). Sobral. Brasil.

Pinho, G. C. S.., Sant Ana Junior, R., Vieira, G. L.( 2011). Manifestações Patológicas causadas por construções edificações vizinhas. $53^{\circ}$ Congresso Brasileiro do Concreto. Florianópolis. Brasil.

Portella, C.S.A. (2013). Avaliação da durabilidade de concretos estruturais produzidos segundo as prescrições da NBR 6118:2007, quando expostos à névoa salina da Praia do Futuro, em Fortaleza. Dissertação (Mestrado em Engenharia Civil: Estruturas e Construção Civil) - Universidade Federal do Ceará. Brasil.

Roberto, P.N.S. (2011). Patologias estruturais ocasionadas por falhas de execução e imcompatibilidade entre os projetos aequitetônicos e estruturais (estudo de caso). $53^{\circ}$ Congresso Brasileiro do Concreto. Florianópolis. Brasil.

Sales, J. C.; Santos, M. W. L. C. ; Brandão, F. S. ; Braga, W. A. ; Laureano, N. S. P. (2014). Patologias na Catedral Metropoltana da cidade de Fortaleza no Brasil: Igreja da Sé. International Congress about Pathology and Structures Rehabilitation - CINPAR 2014, Santiago, Chile.

Silveira, F. F. F. (2021). Patologia na construção civil: um estudo de caso das principais manifestações patológicas em prédios públicos do município de Cruz-Ce. Trabalho de Conclusão de Curso (Graduação em Engenharia Civil) - Universidade Estadual Vale do Acaraú. Sobral. Brasil.

Santos, R. G. (2018). Análise das manifestações patológicas apresentadas na estrutura de concreto armado do edifício Alba Carneiro. 2018. Trabalho de Conclusão de Curso (Graduação em Engenharia Civil) Universidade Estadual Vale do Acaraú. Sobral. Brasil.

Teodoro, B.G.P., Antunes, M.A., Lopes, P.H.C.R., Silva, L.C.S.L.E. (2020). Avaliação patológica da capela Nosso Senhor dos Passos em Córregos/MG. Congresso Brasileiro de Patologia das Construções. Online. 
Vasconcelos, L.H.L. (2018). Análise das manifestações patológicas nas edificações do acampamento Joia na cidade de Cruz - CE. Trabalho de Conclusão de Curso (Graduação em Engenharia Civil) - Universidade Estadual Vale do Acaraú. Sobral. Brasil. 